\title{
Climate Change in urban water system challenges: towards an integrated anticipatory planning approach
}

\author{
Bruno MONARDO, Claudia MATTOGNO, Tullia Valeria DI GIACOMO, Luna KAPPLER, \\ 'Sapienza' University of Rome, Focus Research Center, Italy
}

\begin{abstract}
The main goal of these reflections is to investigate and highlight innovative approaches in Climate Change driven policies, aimed at overcoming the waterfront cities' critical aspects. The 'River contracts' experience, explored through two case studies in the Roman hydrographic basin, is conceived to tackle the increasing vulnerability of its territory, looking for a sensible attitude towards the integration of water systems, green corridors and open spaces, with actions to be planned and shared through participatory democracy's steps. Anticipatory adaptation looks ahead to the project scenario trying to implement policies and strategies preventing potential disasters. Creative design and conscious management embracing different spatial scales play a crucial role in enhancing the anticipatory adaptation and resilience approach. The variety of trends, contexts and spatial scales highlights that it is definitively time for fostering the 'adaptation approach', supported by mitigation strategies, with a clear twofold aim: risks to be minimised and potential opportunities to be caught.
\end{abstract}

\section{Keywords}

Climate Change issue, waterfront cities, anticipatory adaptation, urban planning innovation, river contracts

\section{The conceptual framework}

These reflections are related to a EU interdisciplinary research project ${ }^{1}$ aiming to explore the impact of Anthropocene Climate Change of European territorial and urban waterfronts domains. The main goal is to expand the realm of possibilities so that urban waterfronts can adapt, transform and create opportunities to be meaningful areas for the community. Virtuous planning boosts Public-Private Partnership incorporating adaptation strategies into planned actions through the evolution of intriguing sustainable policy tools: the 'River contracts' born in France forty years ago and widespread all over Europe. They are not to be considered mere 'new plans' but mostly represent an innovative methodology process for water management as their effectiveness is strongly based on the active participation of local actors. Supported by Governments at different levels and jurisdiction from EU to local, they are exemplified by applications in national and transboundary territories. A particular attention is devoted to the stakeholders to be involved and to their role in the adaptation process to climate changes in local or regional bottom-up initiatives. Looking at the most advanced economies across the world it is possible to focus on different cultural models through the comparative analysis of specific case-studies. Findings and lessons are expected to be useful in order to extract relevant suggestions for the innovation of integrated strategies in a climate changing environment. In the Italian context some experiences are struggling against superimposing competences, leading to conflicting actors scenarios, and to the need of a cultural change in order to boost a new territorial vision. Above all there is a strong difficulty for stakeholders to think at a

1 This paper is related to the dissemination of the EU research project 'SOS Climate Waterfront', Horizon 2020, Marie Sklodowska-Curie RISE, 2018-2021 
basin scale and there is a challenging urgency to overcome administrative and sector divisions (Guerra, 2012). The main goal of these notes is to investigate and highlight innovative approaches in Climate Change driven policies to overcome these critical aspects.

The research addresses the gap in Italy between the conceptual situation with theoretical reflections and the stratifications coming from the territory to be solved through innovative tools that can allow an adaptive approach to the land care. The research highlights the inner potential of integrated anticipatory planning rebounds in the city of Rome and its surroundings where cooperation and collaborative experiences take place with a virtuous "multi-actor approach" (Klijn, Teisman, 1991). The research follows the inductive method and the classic case-study interpretation keys (Yin 1984) developed with a qualitative approach and supported by direct sources and interviews. The case studies choice is referred to the main methodological approaches active globally on what can improve the response to hydrological stress, mitigate the impacts and, effectively, optimize the management of resources towards sustainability.

\section{Climate Change, water systems and planning strategies}

Nowadays, it is clear that Climate Change impacts on cities will keep on blowing up in the incoming years (IPCC 2014): sea and riverfront cities with their whole hydrographic systems will be more and more vulnerable to extreme events such as heavy precipitations leading to devastating floods and alarming sea level rise (EEA 2012). Therefore, the emerging imperative for contemporary metropolitan and urban communities lies in the ability to develop policies, strategies and project solutions able to prevent incumbent disasters. In the last decade the scientific debate about the issue of 'anthropogenic Climate Change' and its effects on human settlements has been shifting towards the capabilities of public policies and integrated partnerships to rethink visions and implement virtuous, complex strategies in order to face the increasing threats and manage the vulnerability of contemporary regional and urban realm. There's no doubt that the primary determinant of the location of urban settlements is related to water, coastal territories and rivers. The origin of cities is strongly related to river and sea waterfronts ensuring economic advancement, social development and cultural progress to the whole human society. They have influenced the shape and distribution of cities and determined their economic destinies and social relationships. Apart from supplying essential water resources, rivers and floodways have permitted the pervasive transportation of passengers, goods and services among different ports and water hubs. Since the origin of human settlements, however, the relationship between cities and their rivers has been pretty complex and can be interpreted as an everlasting challenge of coexistence between two different systems (Ureña 1999): on one hand the river environment, characterized by change, diversity and the occasional occupation of space during flood events, on the other hand the urban environment, historically homogeneous, compact and mineral. Each city-river case is unique, and riverfronts have been treated quite distinctly by urban and regional planning depending on the river environment features, for instance their basin hydro-morphology and flood events related to water regimes, or the urban fabric issues as the creation of dense hubs or marginalized spaces governed by 'vicious' or 'virtuous circle' rationale (PenningRowsell 1997).

In the European case, during the 1980s and 1990s plans were implemented for the environmental restoration and urban regeneration of riverfronts, and they have allowed the natural environment to be integrated into the urban fabric. The great European capitals as London, Paris, Amsterdam or Lisbon, as well as other relevant urban realities like Hamburg, Manchester, Rotterdam, Lyon or Genoa represent paradigmatic examples of the strategic regeneration of their waterfront systems pursuing the synergic 
relationship between the open environmental space and the city pattern (Santasusagna et al. 2015). Some scholars have argued about the 'fluid city paradigm' (Carta 2016), merging knowledge and action towards an integrated and creative planning approach in which waterfront regeneration is chased as the fundamental interpretation key of urban redevelopment strategies. The emerging policies for managing urban river areas responded, firstly, to the emergence - in the broadest sense - of the environmental movement and secondly, to the will to reconcile the restoration of the river ecosystem with its use by the city dwellers. Riverfront areas have gone from being perceived as "marginal" and "marginalized" spaces (Panareda 2009) to forming part of a new model that, to varying degrees, reassesses their social, economic and landscape value, enabling citizens to enjoy a city that has managed to turn around and face its river again (Ribas 2012). Undoubtedly, these new management policies have been favoured by the adoption, in 2000 and 2007, of the Water Framework Directive and the Flood Directive respectively. Mentioned EU Directives and related implementations in the Member States contributed to fix and monitor specific targets concerning environmental quality, which the urban planners of the $21^{\text {st }}$ century assumed as their main goals within attitudes and styles that emphasize, above all, the preservation and restoration of water bodies and the related regeneration of the urban realm.

Through the Rome river system case and the general strategy of the so called 'River contracts', the authors' goal is to investigate and highlight innovative approaches in Climate Change driven policies, aimed at overcoming the critical aspects of riverfront cities. Looking at the most advanced economies across the world it is possible to focus different cultural models through specific case studies to be selected starting from the consolidated statement of the scientific disciplinary community about the distinction of two opposite great categories of responses to extreme events: reactive or anticipatory (Repetto 2008).

Reactive adaptations occur after a 'disaster' has already taken place. They try to overcome inattention beforehand while reducing damages from future, similar events. Often, they are just an over-response in an emergency situation without durable impacts nor a positive balance between efforts and outcomes. Anticipatory adaptation, instead, looks ahead to the project scenario trying to implement policies and strategies before an extreme event or any other risky impact could occur. Virtuous planning can ensure that damages (and costs) are minimized by incorporating adaptation strategies into planned actions. As some schools of thought have highlighted (Shaw et al. 2007), creative design and conscious management of urban environment embracing different spatial scales (from single blocks to neighbourhoods, from cities to metropolitan areas and their regional context) plays a crucial role in enhancing the anticipatory adaptation and resilience of the entire urban ecosystem. The variety of trends, contexts and spatial scales representing diversity, reach unity's strength through an integrated-anticipatory planning. This shows that it is definitively time for the 'adaptation approach', supported by mitigation strategies, with a clear twofold aim: risks to be minimised and potential opportunities to be caught.

\section{River Contracts}

\subsection{Strategic and negotiated planning instruments}

The challenges posed by climate change on the urban water system can be addressed through the River Contracts which are useful tools for the regeneration, management and enhancement of territories that are characterized by the presence of a water body. River Contracts are part of a wider set of instruments that refer to different categories of water bodies: lakse, coasts, transitional waters, estuaries and groundwater. The literature on the discipline is dealing with describing the general features and specificities of the river contract understood as "the outcome of an integrated inclusive decision-making 
process" (Carter and Howe, 2006), which allows to undermine the traditional forms of water management, based on top-down hierarchical relationships, and to overcome their strictly technical and sectoral character (Eckerberg and Joas, 2004). On the basis of a voluntary agreement, the River Contract mobilizes the participation of all the main players in a river area for the definition and implementation of a shared strategic framework (Affeltranger and Lasserre, 2003; Cannavò, 2018). River Contracts follow an homogeneous structure that responds to an incremental processes of strategic objectives and levels of interaction, articulated into five steps in which participation has a transversal role of interconnection. River Contracts represent voluntary instruments of strategic and negotiated planning that pursue the protection, correct management of water resources and the enhancement of river territories together with safeguarding from hydraulic risk and contribute to local development. The River Contract can collect, in a shared process, initiatives from below, and become a key opportunity for the comparison between the different stakeholders and civic instances to redevelop the river as a common good, solving the overlapping of competences they have that has caused strong immobility in Italy on the water management sector.

In a European framework, these tools contribute to the pursuit of the objectives of environmental legislation, with particular reference to the Water Framework Directive (2000/60/EC), the Floods Directive (2007/60/EC), the Habitat Directive (1992/43/EEC), the Marine Strategy Framework Directive (2008/56/EC). They represent, in fact, a useful tool for the prevention and reduction of pollution, the sustainable use of water, the protection of the environment and aquatic ecosystems; mitigation of the effects of floods and drought as well as for the coordination and consistency of the actions and interventions envisaged for the implementation of the aforementioned directives.

\subsection{European experiences}

River Contracts were born in France in 1981 as "Contrat de Rivière" and the first experience took place at La Thur river in 1983. Due to the gained success, this method was soon to be expanded and adopted in the entire country, especially for the tributaries of the Rhone. In fact, more than 150 River Contracts are operative today in France, which cover approximately $10 \%$ of the national territory. This methodology today is being implemented in other European countries and the EU supports these practices through different programmatic tools. In the European context, for example the experience of the River Contracts in the Walloon Region in Belgium represents a reference point of these innovative methodologies, as it involves all of the interested local actors of the entire area. River Contract Management Committees were constituted to ensure a strong participation of citizens and associations, as well as involving local authorities and government bodies. They have promoted the direct participation of all actors in the efforts for the river banks management and recovery, resources inventories, elimination of invasive plants, water cleansing and generally to all those initiatives foreseen in the Contract.

\subsection{River Contracts in Rome and its surroundings}

River contracts have been formalized in Italy starting from 2007 with the National Board, although the first national examples were realized in Lombardy and Piedmont at the beginning of 2000 (the first is the OlonaBozzente-Lura, 2004). They are not urban planning tools, but they are based on the existing planning tools and referring to a specific river, territorial or urban area, so that they can contribute to integrate and reorient local planning and improve the contents of super-ordinate planning. In particular, River Contracts refer to the forecasts of plans and programs already existing in the reference river basin/sub-basin and define an Action Program (PA) shared between all the adhering subjects who mutually undertake to implement it through the subscription of an agreement that can take different legal forms. 
The Lazio Region has adhered to the National Charter of River Contracts (drawn up in the V National Table of River Contracts, Milan 2010), identifying in the River Contracts operational tools aimed at favoring integrated and participatory strategic planning, functional to the achievement of objectives of good environmental quality, hydraulic safety, health.

\section{Virtuous rebounds for the city of Rome and its context}

\subsection{The Tiber River Contract from Castel Giubileo to the mouth}

The Tiber River Contract from Castel Giubileo to the Mouth is a collaborative programming tool that allows to define a shared strategy for environmental improvement and enhancement of the Tiber River in its urban path in the municipalities of Rome and Fiumicino. Its area of responsibility, with a longitudinal development of $60 \mathrm{~km}$, concerns the stretch of the Tiber between the Castel Giubileo Dam (1952) and the arrival at the sea of "Fiumara grande" and the Fiumicino canal. The Tiber River Contract is one of the few cases in which the promoter is an association. Launched with the subscription of the Manifesto by an association of associations named "Agenda Tevere Onlus" in 2017, it counts today about sixty signatories including public administrations, research bodies, universities, professional associations, territorial and voluntary associations. It is not an urban planning tool, but an alliance of purpose in line with existing planning, that aims to resolve conflicts and overlaps. It is a "pact of commitment" between administrations, competent bodies, experts and the territory. The involvement of different stakeholders (public, private, civic) through the principles of horizontal subsidiarity (Ostrom, 2005), catalyzes the efforts to redevelop the river as a common good, activating a process of re-appropriation by the community and rebuilding the relationship between the river and the city.

At the starting point the critical situation of the area concerns different issues to be addressed: hydrogeological risk, land use, occupation of floodplains, overlapping of skills and uncoordinated and punctual interventions. Some sections of the Tiber drainage basin are in conditions of serious hydraulic risk and show evident phenomena of erosion of the banks. The specific flora and fauna ecosystem and the wooded areas of the Tiber, in some cases, are not accessible and are in conditions of decay and abandonment. The river basin of the Tiber is a complex hydrosystem whose water quality is compromised by the confluence of wastewater from the area municipalities. From a socio-economic perspective the anthropogenic activities that take place in the sub-basins produce their effects within the environmental corridors, and therefore in the floodable areas, especially for the phenomenon of hydraulic risk, waterproofing and soil consumption. The image that emerges from the land uses in the Roman area depicts territories undergoing strong transformation. There are consistent phenomena of settlement dispersion linked to the increasingly consistent occupation of the Agro Romano by new residential settlements next to the persistence of some industrial agglomerations and cultivated agricultural land. Numerous sites of historical-archaeological value are in decay and neglected conditions, but hide a great potential in terms of cultural heritage and attractivity. The $8 \mathrm{~km}$ embankments begun in 1876 have segregated part of the river corridor from the city, denying proper connections.

At the same time, the system of public and institutional responsibility that governs the banks of the Tiber has been characterized by overlaps, stratifications and fragmentation. The interventions that have been carried out are reactive, related to emergencies or sporadic. They have not adequately considered the common perspectives nor the anticipatory approach although the planning guidelines and regulations have aimed at unitary characterizations over time. Furthermore, the fragmented management made it difficult to pursue a collective perspective. A common voice and a shared framework are needed in order to make 
the Tiber a common good to be returned to citizenship through participation and proactive interaction between public and private actors who live and govern the city. Social instability, legal uncertainty, concessional fragmentation, abandonment and temporary illegal occupation need decisive, targeted and shared actions.

The River Contract catches the opportunities underneath the presented critical issues setting a strategic path that defines general and specific objectives, actions, interventions, responsibilities and timing. General aims are unifying competencies and socio-economic resources, promoting awareness, strengthening the existing know-how to redevelop and enhance the banks of the Tiber through an "open program" that expresses a convergent and integrated plurality of projects. Urban enhancement is meant as the regeneration of the Tiber as a system, accessible to all, clean, safe and open to social, cultural, sporting and entrepreneurial activities that contributes to giving a more liveable urban dimension to a polycentric Rome. At the same time urban interventions have to guarantee no negative impacts on biodiversity and water management. Social empowerment is to be achieved by sharing knowledge through big data accessibility; the virtuous process of re-appropriation for the community can be addressed by decision makers through the implementation of a collective interest project. The first action beginning in 2017 with the Manifesto was the process of building the knowledge system focused on the coordination of planning indications for management purposes. The knowledge system has been collected into the Unitary Database of the Tiber which included the coordination of planning indications for management purposes, the reconstruction of the role of institutional subjects and of the related management and planning skills. The authorities and related plans are: District Authority Tiber Basin Plan "Piano stralcio 5" (PS5), Municipality of Rome comprehensive plan "Piano Regolatore Generale" (PRG), Lazio Region widearea plan "Piano Territoriale Paesistico Regionale" (PTPR), Metropolitan City of Rome, Harbor Office. The integration of strategic policies anticipates technical solutions related to water quality, hydraulic safety, biodiversity and environmental protection. The focus on water quality is firstly about the analysis and evaluation of hydromorphological discontinuity, presence of floating waste, self-purification capacity of the river, monitoring systems, naturalness of the banks and alien species, confluence of the Aniene river, ecological connectivity, hydrogeological state, secondary lattice, microplastic contamination, water resource management models. Hydraulic safety concerns the reconstruction of the cognitive framework of the risk represented by water and flood Management plans, the lamination plan and forecasting modeling systems. Biodiversity and environmental quality have to be restored starting from the characterization of the trophic, functional and environmental relationships between natural communities and the analysis of the historical factors that most influenced the dynamics of transformation of the biotic component of the river.

The specific objectives of the Tiber River Contract are highlighted in the 2018 Strategic Document. They include environmental sustainability, accessibility and usability, re-appropriation of bank areas for public use, redevelopment of the river as a common good, enhancement and promotion of existing projects, hydraulic defense of water quality, public oversight through the presence of citizens. The objectives have been specified during time in strategic axes such as updating and development of the cognitive framework, hydraulic safety, water quality, biodiversity and ecological functionality, river-city relationship, fruition, active participation.

The Tiber River Contract perspective is structured on a double-layered action consisting of short-term spot projects and mid-long term structured interventions within the River Contract. Spot initiatives are aimed at building awareness about the opportunities offered by the river and strengthening a common perspective of re-appropriation and are represented by "Piazza Tevere" and Tiberis. Public and private 
entities coordinated by Agenda Tevere have supported the Special Tiber Office of Rome in the restoration of the so called "Piazza Tevere", the area on both the banks from Ponte Mazzini to Ponte Sisto. The project consists of a temporary exhibition in which urban reality and nature, water and art, coexist and feed each other, creating a permeable gathering "square". An unexpected landscape ideally unites the two shores and creates a new public space aimed at integrating social and ecological issues in a form of socialization. The project is the opportunity to discuss the benefits that nature and the river can give to the city to fight the climate emergency. The initiative stems from the "Strategie Green2020" ("Green2020 Strategies") project of the Italian Landscape Association (AIAPP) and the Association of Green Builders ("Assoverde") and was conducted in accordance with the Strategic Resilience Plan of Roma Capitale. Piazza Tevere has been implemented through a system of sponsorships and a network of collaboration between public bodies, multisectoral associations and private companies (Agenda Tevere, AIAPP, Tevereterno, Assoverde, Italgas, Terna and ACEA). Firstly inaugurated in 2018, Tiberis is the municipal set-up downstream of Ponte Marconi on the left bank overlooking the Tiber. The project saw the implementation of the design concept and the setting up in 2019 and 2020, increasing in quality thanks to the partnership with Agenda Tevere and private partners (Italgas, Terna, AIAPP, Assoverde, Polidro Srl for irrigation systems and Tecma for materials).

These test initiatives will be improved and converge in a broader scenery of mid-long term structured interventions that will be addressed through the River Contract by the first Three-Year Action Program and the following ones covering at least thirty years. The Three-Year Action Program expected to be signed within 2021 has the aim of defining actions, interventions, financing, times and actors for the implementation of permanent and effective changes in the area. Each signatory of the Manifesto will have the responsibility of a single action or complex project under the comprehensive monitoring system of the Program. Lazio Region is financing the process that will lead to the definition of the contract thanks to a public tender procedure.

At the same time, the difficulties of harmoniously coordinating the many possible initiatives with the numerous overlapping public competences has prompted the Region to find an innovative and multipurpose tool capable of overcoming divisions: the Participation Foundation "Tevere per Tutti", promoted with its own regional law. The Participation Foundation is open to the equal participation institutional and voluntary actors intending to make the Tiber an attractor of economic activities, environmental qualities, naturalistic beauties and cultural opportunities. It has the purpose to address the innovative, sustainable and intelligent possibility for citizens and tourists to enjoy the Tiber natural, cultural and landscape beauties capable of improving the quality of life and preserving the usable river heritage for future generations and for humanity. These objectives will be supported by incentivizing, stimulating and enabling public and private investments of quality and river enhancement. The integration of regional funds with the contribution of social, civic, cultural actors will allow a more participatory maintenance, programming, strategic planning and the surveillance of river areas. The Foundation will disseminate the image of the Tiber with appropriate marketing and communication operations and support national and international events and initiatives that deal with river issues and ecological infrastructures, bioeconomy, sustainability and innovation. The River Contract will be strengthened giving voice to committees, associations, citizens, users and tourists through the promotion of the Foundation's activities. In this process training local operators and stimulating partnerships with universities and research centers, responsible and innovative companies on experimental projects on climate change and the circular economy will be essential. Both the Foundation and Tiber River Contract follow an incremental process, continuing to welcome new actors and initiatives that will be able to build future Action Programs. 


\subsection{The contract of the Aniene river from its sources to the confluence in the Tiber}

The Aniene River is a main water body that extends for over $100 \mathrm{~km}$ and originates in the Province of Frosinone on Mount Tarino within the Simbruini Mountains Regional Natural Park. The water catchment area of the Aniene River, whose surface is approximately $1,500 \mathrm{~km}^{2}$, is a sub-basin of the Tiber River and the Aniene River constitutes its main tributary in the Lazio Region. The course of the Aniene river passes through the provinces of Frosinone and Rome and crosses the territory of 17 municipalities. The confluence in the Tiber River is located in the urban territory of the Municipality of Rome. The watercourse is generally divided into upper, medium and low courses: the upper part is represented by a substantially mountainous territorial context in which the Aniene valley represents the main link between the communities and goes from the sources to Subiaco, the middle valley gravitates around Tivoli (famous for its thermal baths and for its magnificent ancient roman villas), extending from Subiaco, and the lower valley is configured downstream of the waterfall in Tivoli up to the urbanized part of Rome and the confluence with the Tiber River within the Regional Nature Reserve of Aniene Valley (EUAP1045). The geography of the Aniene basin represents a vast and heterogeneous area affecting the territory of 76 municipalities and has a decisive influence on the environmental state of the Tiber River. In particular, in the low courses, the Aniene River does not reach the ecological quality standards imposed on the Member States by the EU Water Framework Directive 2000/60/EC. The territory of the hydrographic basin is characterized by hydrogeological fragility also in consideration of the degree of soil sealing and waterproofing of the areas near the watercourse, especially in the lower course, pollution of the watercourse and the need to preserve the historical and naturalistic heritage. The presence of the Aniene river contributes to characterize the crossed territory also from the microclimatic point of view.

The territory of the Aniene valley is animated by various stakeholders who have undertaken a collaborative strategy to define and implement the organizational and technical-administrative aspects of the "Towards a River Contract" project. In order to promote the involvement of stakeholders and the exchange of knowledge, the meetings have so far taken place at the various locations of the upper, medium and low course under the slogan of "Let's make the future: the River Aniene we want". Direct participation, the guide of the Technical Secretariat of the Aniene River Contract, makes it possible to integrate the contributions of expert and non-expert knowledge and to share ideas and address the critical elements in the different themes of environment, risk and local development. The participation process has the purpose of soliciting initiatives, events and synergies between the territorial actors, in order to contribute to the construction and implementation of shared and integrated government policies of the river system, with specific reference to the objectives of protecting the water resource, managing the hydraulic risk, protecting the river ecosystem, enhancing public heritage and local development in a climate changing environment. A plenary meeting of the Basin Assembly is convened to summarize the emerging issues and start the subsequent phase of collecting preparatory proposals to define the Action Program of the Aniene River Contract with objectives, actors, obligations and commitments, times and methods, criticalities and guidelines, human and economic needs. Dissemination of process' activities takes place through a plurality of tools and has also involved the creation of an interactive cartography.

The promoter of the Aniene River Contract is the Public Authority "Comunità Montana dell'Aniene" CMA (Aniene's Mountain Community). The formalization of the Document of Intents for the River Contract and the activation of the related Basin Assembly took place on $19^{\text {th }}$ July 2018. Following that date, the territorial groups were divided in the upper, medium and lower valley of the Aniene River. In this way, a homogeneous set of thematic issues are treated collectively in line with Environmental lows: 
environmental quality of the watercourse, conditions of flood risk and the geomorphological dynamics of the river area as well as local development related to the management of the watercourse.

The entire river stretch has been analyzed to identificate measures to be taken in the short (2025) and medium term (2050). The identification of integrated strategies and actions will be implemented within the European structural and investment fund programmes. More than a year after the start of the "Towards a River Contract" project, the territorial listening phase has been completed: the next phases include the drafting of the strategic document that defines the scenario integrating territorial planning objectives with local development policies and the Action Program. Unfortunately further meetings to define the planning actions to be implemented have been interrupted due to the Covid-19 health emergency.

The Aniene River Contract intends to bring together the various existing stakeholders by recalling institutions and individuals to a non-sectoral but integrated vision aimed at the rebirth of the Aniene Valley considered as a common good to be managed collectively. In particular, the Document of Intent of the Aniene River Contract was signed by more than 70 public and private entities and a continuous addition of signatories is underway thanks to the activities of expanding the network of stakeholders. In addition to the CMA Public Authority, among the most active subjects involved there are municipalities, cultural, sports, tourism, environmental and trade association, public services authorities, labor unions, other sectoral public bodies, individuals and companies. All the actors of the Aniene River Contract are required to respect a form of co-responsibility in the pride of belonging to a valuable ecosystem. This important tool of territorial governance based on participation can activate processes of co-evolution of the territorial system and anticipatory adaptation and has the opportunity to promote bottom-up initiatives through continuous and programmatic dialogue between the different stakeholders and civic instances, so that they can be heard and strengthened. The system's transformation frame moves towards promoting resilience with respect to climate change and towards anti-fragility territories paths (Taleb, 2012). It can contribute to improving the knowledge that communities must have of territorial vulnerabilities and the effects of human activities. In this way it represents a tool to increase social awareness and include society in the identification and implementation of solutions for river enhancement for climate adaptation and resilience. The Aniene River Contract represents in the upper valley the flexible tool to unite a territory that has local communities connected mainly by the ancient streets Tiburtina Valeria and Sublacense. By expanding the concept on a large scale, it is a question of uniting the mountain territories with the city of Rome. In the lower valley, however, this can allow integration with other similar initiatives for the development of territories and protection of water bodies such as the Tiber River Contract and the Aniene Safe Project of the III Municipality of Rome.

The Aniene River Contract, as an inclusive participatory tool, is strongly influenced by the presence and activities of the participating actors. Furthermore, being a process with a medium-long time dimension, it can be influenced by institutional transformations and by the loss of continuity in the dialogue with public bodies which often have planning linked to the temporal duration of the mandate. A particular case, in fact, is represented by the CMA which leads the Aniene River Contract which is a local body with statutory autonomy, with the aim of promoting the enhancement of its territorial scope. The Water Framework Directive (2000/60/EC) established the abolition of the Basin Authority according to the aggregations of the District Authorities, therefore the Tiber Basin Authority, the main Public Administration operating in the water resources sector, has now become the District Authority of the Central Apennines with a notable expansion of its territorial extension. From an organizational point of view, therefore, it remains a critical issue for the Aniene Valley to coordinate a large number of cross-sectoral and multilevel stakeholders as 
well as the coordination of private participation. While a financial support remains for the process a challenging issue, a virtuous initiative is exemplified by the activity of the III Municipality of Rome that was able to direct funding towards a inhabitants and associations strongly desired local intervention, thus managing at the same time to solve a safety problem and to develop an initiative to promote the Aniene river with the realization of docks along the river. The main objective that was addressed was in fact to make a livable space and therefore a safe space. From the point of view of preserving the quality and quantity of the water resource, however, among the major critical issues for the Aniene Valley there are the water pollution issues in the lower course and the contrasting needs for pumping and to maintain the minimum vital flow of the watercourse in the upper course. These critical issues, exacerbated by climate change, are flanked by the development needs of the 31 Municipalities of the Aniene Valley and the presence of environmental protection constraints that reduce the possibility of carrying out new initiatives. As regards administrative issues, on the other hand, there is difficulty with respect to the low technical level of public officials who deal with the river contract and the need for territorialisation of the actions which can however find a useful tool in the interactive cartography. The main outcome will be to achieve convergence between top-down strategies and bottom-up practices, transforming discontinuous actions of different measures into systemic and organized development models in the various thematic areas of environment, risk and local development. The process towards the Aniene river contract by integrating and clarifying skills and duties will make it possible to invest in environmental protection, improve risk management and river maintenance also from a Sendai Framework perspective (Sendai Framework's Priority 2: Strengthening disaster risk governance to manage disaster risk) and optimize funding for incremental territorial development. Strengthening disaster risk governance fosters collaboration and partnership across mechanisms and institutions for the implementation of instruments relevant to disaster risk reduction and sustainable development (UNODRR 2015).

\section{Open issues: 'River contract' as 'flood resilient' and synergic process}

The Tiber and Aniene 'River contract' policies deliver useful findings and lessons in order to extract relevant suggestions for the innovation of environmental integrated strategies and specific projects to be applied in Italy. In particular, virtuous rebounds can be expected for the 'Eternal city' coping with its planning paths. River Contracts are conceived to contrast the increasing vulnerability of its territory and look for a sensible attitude towards the integration of water systems, green corridors and open spaces to be planned and shared through participatory democracy's steps.

The Roman case study choice is embedded into the main methodological approaches, active on what can improve the response to the territorial hydrological stress, mitigate the general and local impacts and, effectively, optimize the resource management towards sustainability and resilience. In the international scenarios, scholars and experts specify diverse cultural trends, distinguished by their main focus: strategic policies, technical solutions or their integration.

Resilience is frequently associated with self-organization and adaptive capacity, (Carpenter 2001, Low 2003, Tompkins 2004). Adaptiveness can increase resilience over time, as it is joined in acquiring the capacity to fit changing internal demands and external conditions (Gunderson 2010, Carpenter 2008). These concepts can be translated into key properties of urban resilience to floods and highlight the distinction between resistant and resilient urban territory.

It is widely shared by the stakeholder's arena involved in environmental and urban planning that flood resistance is necessary for cities; however, resilience theory suggests that it erodes resilience of cities to floods (Holling 1996). In fact, flood-control infrastructures confer the city contrasting conditions: dry and 
stable, or inundated and disastrous. With huge dikes, walls and other artificial water control systems, floods occur exclusively from the infrastructure's failure (Tobin 1999). Cities dependent on flood-control infrastructures are highly resistant to floods, but not really resilient, because they have physically adapted to the artificially expanded dry-and-stable conditions to become intolerant of wet conditions.

The 'River Contract' original approach, born about forty years ago in France, and the specific interpretation presented in the Roman case studies, highlight some relevant issues and open problems embedded in the planning historical roots and still present in the regional and urban planning culture in Italy. Italy, as other Mediterranean countries, is based on the 'Civil Law' juridical dimension, differently from the 'Common Law' Anglosaxon model. The very conception, the same idea of the necessity to set up and re-boost the 'contract' leads us back to the evolution of the intrinsic nature and role of different planning tools and their mutual relationships.

The 'contract' idea is intimately related to the opportunity to give sense and implement an authentic 'strategic approach', not really a 'conventional plan' but mostly a 'new alliance' among all different actors, privileged and recessive, originally sustaining various and sometimes conflicting interests in the city arena; this pact, signed by public bodies with different missions, jurisdictions and competences, as well as by private stakeholders and non-profit entities, is the basis to deliver an effective contribution in order to focus and implement inclusive, shared virtuous scenarios for the whole community.

The implementation of the new philosophy of 'River Contracts' is expected not to repeat the vices of the past in which every institutional actor claimed to impose the primacy of his political, economic, social or environmental vision, reflecting the choices on the physical-spatial dimension through a specific plan. In fact, the culture of planning in Italy, and in general in the 'Civil Law' countries, since the Second World War has lived up to the very beginning of XXI century in the heated debate on which was or should be the dominant, privileged interest, and therefore the 'plan of plans'. The greatest conflict has developed within the vast galaxy of public subjects (Ministries, Regions, Basin Authorities, Metropolitan Areas, Provinces, other inter-municipal bodies, Municipalities) which have pursued the continuous promulgation of legislative measures aimed at reaffirming the individual primacy by upsetting the hierarchies of the various territorial and urban planning tools. On the contrary, in recent times 'River Contracts' have been interpreted in Italy, and in the Roman case in particular, as an innovative path for water system management: their ambition is to represent a complex process able to coordinate the heterogeneous visions of national, regional and local actors, chasing synergy opportunities within different visions, plans, programs and projects.

\section{Authors' contributions}

This paper is conceived as the result of a common effort by all authors. However, B. Monardo wrote sections 2. and 5., C. Mattogno section 1., T.V. Di Giacomo section 4.2, L. Kappler section 4.1 while the whole section 3. was authored by both T.V. Di Giacomo and L. Kappler.

\section{References}

Affeltranger B., Lasserre F., (2003), 'La gestion par bassin versant: du principe écologique à la contrainte politique le cas du Mékong'

Bossard M., Feranec J., Ot'ahel' J. (2000), Corine Land Cover-Technical Guide

Cannavò P., (2018), 'Verso il parco urbano del Tevere', Tracce Urbane, No. 4

Carpenter S. R., Brock W. A., (2008), 'Adaptive capacity and traps', Ecology and Society, 13(2):40

Carpenter S. R., Walker B., Anderies J. M., Abel N., (2001), 'From metaphor to measurement: resilience of what to 
what?', Ecosystems, 4 (8), p.765-781

Carta M., Ronsivalle D., (eds. 2016), 'The fluid city paradigm: Waterfront Regeneration as an Urban Renewal Strategy', Springer, Dordrecht

Carter J., Howe J., (2006), 'Stakeholder participation and the Water Framework Directive: the case of the Ribble Pilot', Local Environment, 11(2), p.217-231. Doi: 10.1080/13549830600558564

Eckerberg K., Joas M., (2004), 'Multi-level Environmental Governance: a concept under stress?'. Local Environment, 9(5), p405-412. Doi: 10.1080/1354983042000255315

Guerra S., (2012), 'Disputed or Shared Territory? The Italian Experience of River Contract: New Relationship between River and its Region', Planum - The Journal of Urbanism

Gunderson, L. H. (2010), 'Ecological and human community resilience in response to natural disasters'. Ecology and Society $15(2): 18$

Holling, C. S., (1996), Engineering resilience versus ecological resilience. in P. C. Schulze, editor. Engineering within ecological constraints. National Academy Press, Washington D.C., USA. p. 31-43

Klijn E.H., Teisman G.R. (1991) Effective Policy Making in a Multi-Actor Setting: Networks and Steering. In: in 't Veld R.J., Schaap L., Termeer C.J.A.M., van Twist M.J.W. (eds) Autopoiesis and Configuration Theory: New Approaches to Societal Steering, Springer, Dordrecht

Liao, K., (2012), 'A theory on urban resilience to floods. A basis for alternative planning practices', Ecology and Society, 17(4): 48.

Low, B., E. Ostrom, C. Simon, J. Wilson (2003). 'Redundancy and diversity: do they influence optimal management?' Pages 83-114 in F. Berkes, J. Colding, and C. Folke. Navigating social-ecological systems: building resilience for complexity and change. Cambridge, UK: Cambridge University Press

Ostrom, E., (2005), 'Unlocking Public Entrepreneurship and Public Economies', Working Paper, World Institute for Development Economic Research (UNU-WIDER), DP2005/01

Panareda, J. M., (2009), 'Evolución en la percepción del paisaje de ribera', Boletín de la Asociación de Geógrafos Españoles, 51, p305-324

Penning-Rowsell, E. C., (1997), 'Rius i ciutats: amenaces i potencialitats' in Ribas A., Saurí D. (eds.) Ciutat $i$ riu: l'aigua en l'organització de l'espai urbà, Documents d'Anàlisi Geogràfica, Bellaterra, p23-34

Repetto R., (2008), 'The climate crisis and the adaptation myth', Working Paper 13, New Haven: Yale School of Forestry and Environmental Studies

Ribas, A., (2012), 'Tornar a viure de cara al riu', Revista de Girona, 270, p60-65

Santasusagna A., Tort Donada J., (2015), 'Urban planning in riverfront areas', Miscellanea Geographica, 19 (3), p1421

Shaw R., Colley M., Connell R., (2007), 'Climate change adaptation by design: a guide for sustainable communities', London: TCPA

Taleb, N., (eds.) (2013), ‘Antifragile. Prosperare nel disordine', Milan: Il Saggiatore

Tobin, G. A., (1999), 'Sustainability and community resilience: the holy grail of hazards planning?' Environmental Hazards, 1, p13-25

Tompkins, E. L., and Adger W. N., (2004), 'Does adaptive management of natural resources enhance resilience to climate change?', Ecology and Society, 9 (2):10.

Ureña, J. M., (1999) 'Ordenación de las áreas fluviales en las ciudades: un enfoque metodológico', Revista de Obras Públicas, 46, p4-15

UNODRR, 2015. Sendai Framework For Disaster Risk Reduction 2015 - 2030. [online] Sendai: United Nations. 